ARTIGOS
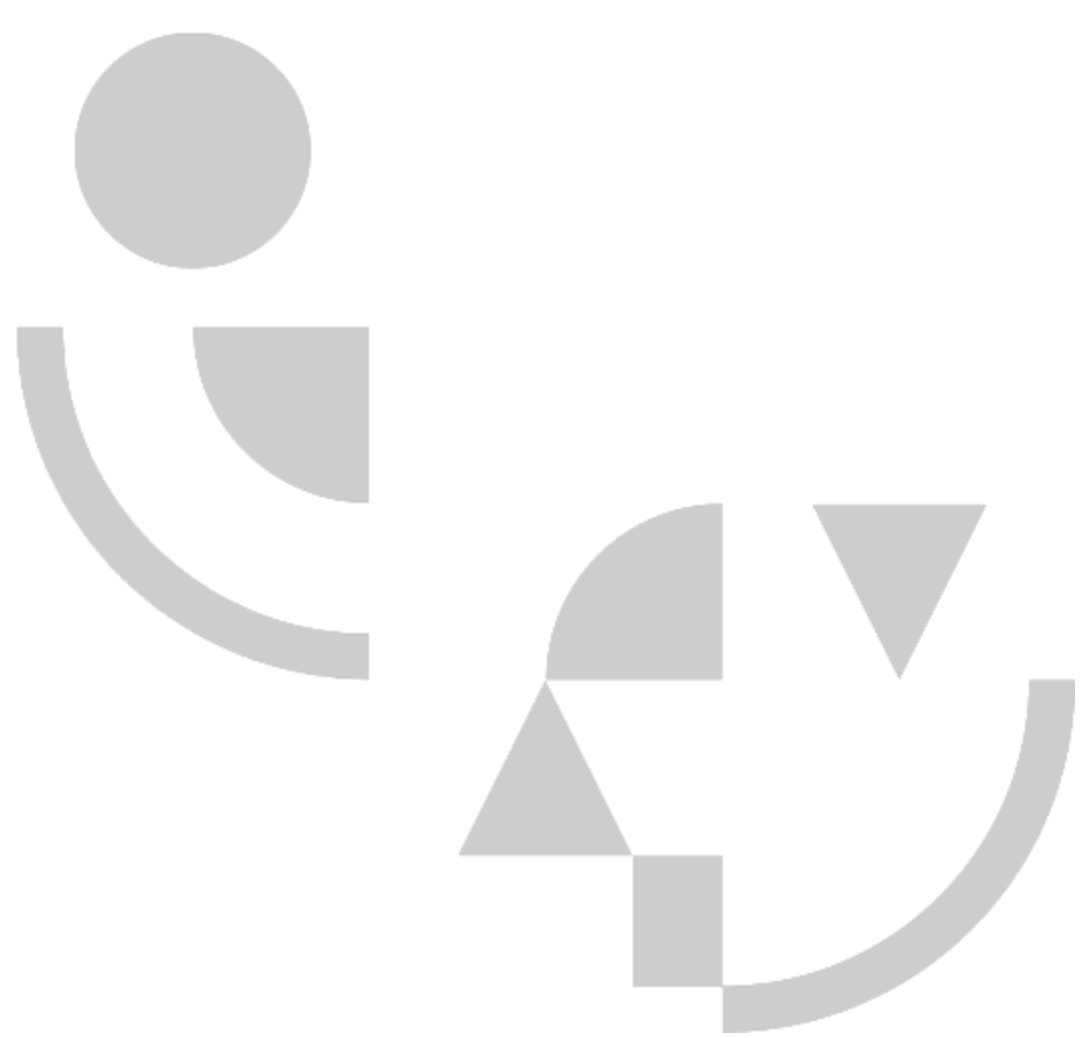
(em branco)
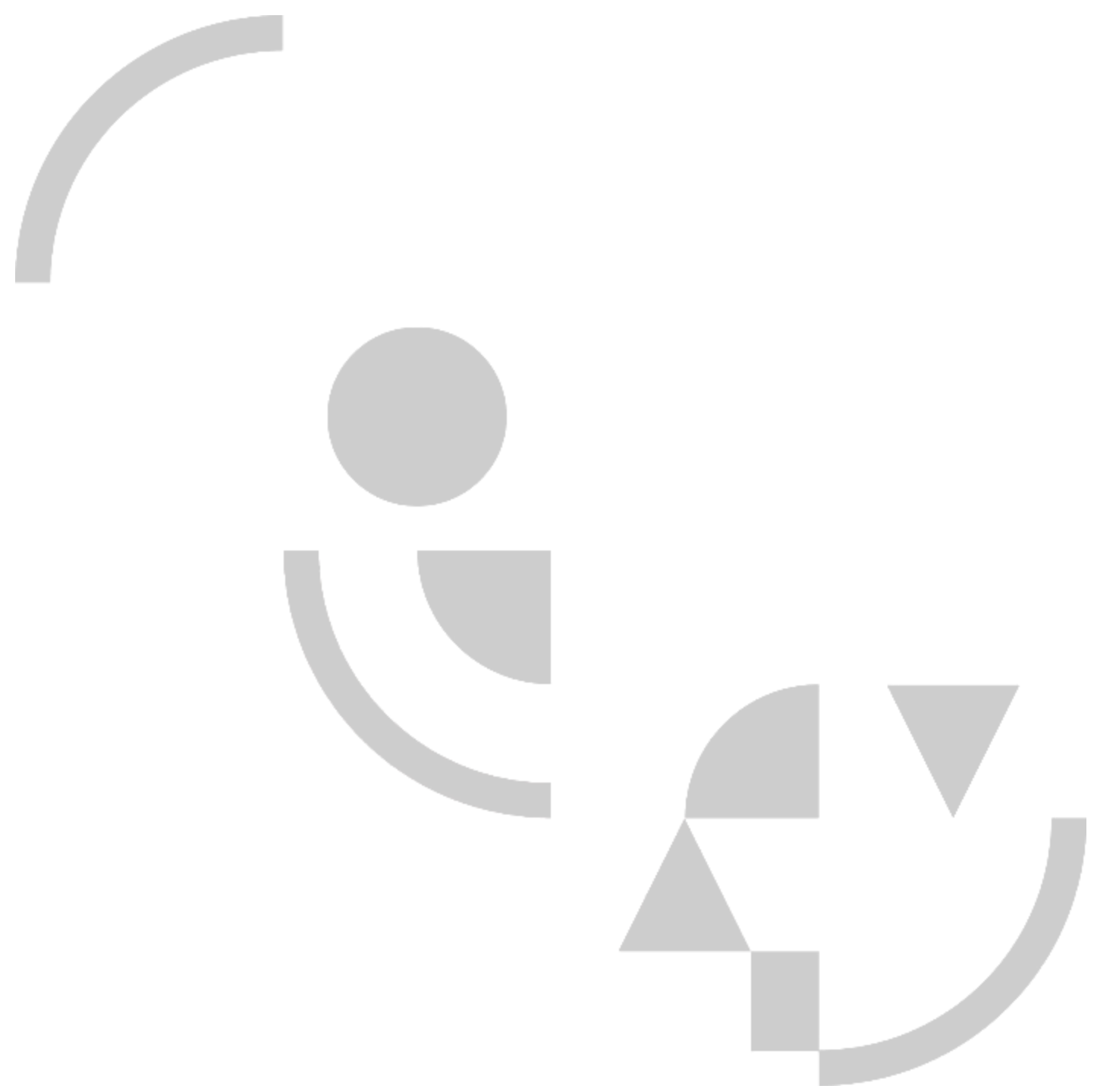


\title{
pro.posições
}

ISSN 1980-6248

10.1590/1980-6248-2014-0113

ARTIGOS

\section{Encontros e desencontros de crianças e adultos na Educação Infantil: uma análise a partir de Martin Buber}

\section{Agreements and disagreements between children and adults in early childhood education: an analysis based on Martin Buber}

\author{
Sonia Kramer* \\ Maria Fernanda Rezende Nunes** \\ Alessandra Evelin Brandolim Pacheco ${ }^{* * *}$ \\ Andrea Ferreira Campos Oliveira***
}

Aline Lopes Martins ${ }^{* * * * *}$

\begin{abstract}
*Pontifícia Universidade Católica do Rio de Janeiro (PUC-Rio), Centro de Teologia e Ciências Humanas, Departamento de Educação, Rio de Janeiro, RJ, Brasil.sokramer@puc-rio.br

**Universidade Federal do Estado do Rio de Janeiro, Programa de Pós-graduação em Educação, Centro de Ciências Humanas, Faculdade de Educação, Rio de Janeiro, RJ, Brasil. fernandanunes@domain.com.br

***Pontifícia Universidade Católica do Rio de Janeiro (PUC-Rio), Departamento de Educação, Rio de Janeiro, RJ, Brasil. lepacheco26@yahoo.com.br

**** Pontifícia Universidade Católica do Rio de Janeiro (PUC-Rio), Departamento de Educação, Rio de Janeiro, RJ, Brasil. andreafco@yahoo.com

***** Pontifícia Universidade Católica do Rio de Janeiro (PUC-Rio). Departamento de Educação Rio de Janeiro, RJ, Brasil. aline_martiins@hotmail.com
\end{abstract}

\begin{abstract}
Resumo
Este artigo apresenta pesquisa sobre práticas e interações em creches e pré-escolas, identificando convergências e divergências. O referencial teórico se baseia na filosofia do diálogo de Martin Buber, e o metodológico, na sociologia da infância, em que as contribuições de Corsaro e Ferreira possibilitam compreender interações e práticas de crianças e adultos em sete instituições de Educação Infantil. Os resultados evidenciaram nas creches: (i) positividades (escuta das crianças, relação dialógica, presença do outro; respeito às crianças; responsabilidade do adulto e preocupação com a qualidade); e (ii) ambiguidades (práticas repetitivas, intenção de ensinar). $\mathrm{E}$ nas pré-escolas: (i) alguma positividade (atividades de criação e diálogo); e (ii) negatividades (invisibilidade da
\end{abstract}




\section{pro.posıções}

criança, atividades instrucionais sem favorecer a expressão infantil; humilhação, constrangimento e anonimato das crianças).

Palavras-chave: interações entre crianças e adultos, práticas educativas, Martin Buber.

Abstract
This paper presents research focused on children and adults interactions in
crèches and preschools, identifying similarities and contrasts. The theoretical
framework is based on Martin Buber's philosophy of dialogue and the
methodology is based on Sociology of Childhood, specially Corsaro and Ferreira,
and their contributions to comprehend the interactions between children and
adults in the seven Early Childhood institutions. The crèches present (i) positive
aspects (listening to the children, dialogical relationship, presence of the other;
respect for the children; adult responsibility and concern for quality) and (ii)
ambiguities (repetitive practice, intention to instruct. The pre-schools evidence: (i)
positive aspects (creative activities and dialogue); and (ii) negative aspects
(invisibility of the child, instructional activities without favoring child expression;
humiliation, constraint and anonymity of the children).
Keywords: children and adults interactions, educational practice, Martin Buber

A Educação Infantil foi assegurada como direito básico na Lei de Diretrizes e Bases da Educação Nacional/LDB (Lei BR no 9.394, 1996). Recentemente, a Lei 12.796 (Lei BR no 12.796, 2013), que altera a LDB, afirmou a obrigatoriedade escolar dos 4 aos 17 anos: pais ou responsáveis devem matricular todas as crianças de 4 anos de idade, mudança a ser implantada até 2016. O Ensino Fundamental foi universalizado nos últimos 20 anos: as políticas públicas têm enfrentado o problema histórico da defasagem idade/série e as dificuldades relativas à alfabetização, à leitura, à escrita de expressiva parcela das populações adultas, juvenis e infantis. O Ensino Fundamental ainda se depara, pois, com o desafio da qualidade das práticas e das interações nas instituições educacionais.

Em que pesem os avanços da universalização, várias pesquisas indicam a qualidade precária da oferta, o que torna urgente conhecer e repensar práticas e interações com as crianças, ou entre elas, na Educação Infantil e nos primeiros anos do Ensino Fundamental. A concepção de criança, como sujeito social e histórico, pessoa que produz cultura e é nela 


\section{pro.posıções}

produzida, justifica pesquisar práticas e interações nessas duas etapas da Educação Básica. Esse é o objetivo da pesquisa aqui apresentada, cujos resultados podem contribuir para a superação dos desafios relativos à qualidade do trabalho e da formação dos profissionais.

O referencial teórico da pesquisa foi delineado com base na filosofia do diálogo, especial em Martin Buber. A metodologia se fundamentou na sociologia da infância: Corsaro (2011) e Ferreira (2008) contribuíram para um conhecimento denso, sensível e ético das interações de crianças e adultos nas sete instituições investigadas.

O artigo está estruturado em três seções. A primeira trata de teoria, metodologia e empiria, explicita os passos da pesquisa, os principais conceitos que a orientam e as opções metodológicas. A segunda e a terceira trazem, nos encontros e nos desencontros entre crianças e adultos nas creches e pré-escolas pesquisadas, as recorrências positivas e negativas. O último item indaga os caminhos para a educação de crianças e adultos.

\section{Teoria, metodologia e empiria em Martin Buber}

A pesquisa teve como objetivo observar, analisar e compreender interações e práticas na Educação Infantil - problematizando, cotejando, comparando e identificando convergências e divergências, aproximações e afastamentos. A fundamentação teórica se alicerça na filosofia do diálogo de Martin Buber (1878-1965), em especial os conceitos de relação, de dialógico, de existência humana, de visão de mundo e de educação. Ao estudar Buber, fez-se necessário outro olhar e escuta para compreender a prática cotidiana.

No livro Eu e tu, Buber (1974) apresenta as duas atitudes do homem frente ao mundo, as palavras princípio $\mathrm{Eu} / \mathrm{Tu}$ e Eu/Isso e suas implicações. Em Do diálogo e do dialógico, Buber (2009) distingue os processos monológico e dialógico, cruciais para a compreensão do "entre", com o conceito de inter-humano. El camino del ser humano y otros escritos (2004) reúne textos publicados em diferentes momentos - "Discurso sobre lo educativo", "Formación e cosmovisión" e "Sobre educación del carácter" -, em que o filósofo conceitua educação e dialoga com as ideias pedagógicas de sua época.

Com base nessas fontes, principais referências teóricas do artigo, o item a seguir aprofunda os conceitos centrais e apresenta a metodologia e a empiria construída. 


\section{pro.posições}

\section{1 - Conhecer o outro: diálogo, encontro e escuta}

Para Buber (1974), a linguagem é portadora do ser, que se instaura por meio das duas atitudes do homem frente ao mundo, explicitadas nas palavras-princípio "Eu-Tu" e "EuIsso". Esses pares de vocábulos, como os denomina o autor, fundamentam a existência e são proferidos pelo ser: em sua totalidade ou inteireza; em sua parcialidade ou limitação. No sentido da inteireza, a atitude Eu-Tu acontece no evento da relação, da totalidade do ser, da presença. No que tange à parcialidade ou à limitação, a atitude Eu-Isso se mostra no fato da experiência, do eu egocêntrico, do objeto.

A relação Eu-Tu exige reciprocidade, uma postura da pessoa para com o outro, de estar entregue à relação. Para Buber (1974), relação é reciprocidade (p. 9). Existem três esferas do mundo da relação em que o Eu-Tu se realiza: a vida com a natureza, a vida com os homens e a vida com os seres espirituais ${ }^{1}$. O parâmetro que Buber usa para estabelecer maior ou menor valor "para uma relação Eu-Tu, a reciprocidade, se baseia numa presença mais completa ou menos completa dos integrantes do evento da relação" (Zuben, 1974, p.157).

A relação Eu-Tu se vincula à presença e possibilita visibilidade das crianças - desafio das instituições educacionais -, onde, muitas vezes, elas se tornam invisíveis. Até o amor acontece no "entre" e é responsabilidade de um Eu para com um Tu. Para Buber (1974, p.17), o contrário do amor não é o ódio, mas a indiferença, o que favorece pensar na apatia de muitos professores e gestores diante das crianças, dos jovens e das condições concretas em que se dão suas práticas cotidianas.

Para o filósofo, a palavra é dialógica. Aí reside a ontologia da palavra, ato do homem em que ele se faz homem e se situa no mundo com os outros. O "entre" permite, como chave epistemológica, abordar o homem na sua dialogicidade.

O movimento básico da vida dialógica consiste no voltar-se para o outro, percebê-lo e aceitá-lo na sua inteireza, se libertar da indiferença. Esse movimento dialógico essencial - ação ou atitude de voltar-se para o outro - se configura como um desafio no mundo moderno, onde o centro são os indivíduos, o consumo, o mérito. Buber (2009) considera um erro grotesco a noção do homem moderno de que voltar-se para o outro seja sentimentalismo ou ato impraticável no tumulto desta vida (p. 57). Para o filósofo, monológico não é se desviar do

\footnotetext{
${ }^{1}$ Escapa aos objetivos do artigo discutir a religiosidade, tema analisado pelo filósofo em várias obras.
} 


\section{pro.posıções}

outro, mas dobrar-se em si mesmo, retrair-se e admitir o outro somente sob a forma da própria vivência, somente como "uma parte do meu eu" (p. 58).

São três os tipos de diálogo (Buber, 2009, pp. 53-54): autêntico, em que há reciprocidade entre os interlocutores (e que pode ser falado ou silencioso); diálogo técnico, necessário para o entendimento objetivo e a informação (o mais comum na vida cotidiana em geral e na vida escolar); e monólogo disfarçado de diálogo. O indivíduo é fato da existência só quando se coloca em uma relação viva com outros indivíduos: o encontro é o reconhecimento do outro em sua alteridade, do mesmo modo que se reconhece a si mesmo. Esse reconhecimento mútuo, de si e do outro, estabelece uma relação essencial que penetra o outro, "quebrando sua solidão em um encontro rigoroso e transformador" (Buber, 2011, p. 145)2. Encontro é estar em recíproca presença (p. 151). O encontro se realiza no entre, e só nele. Não pode ser antecipado, é um evento singular, único e como tal ele acontece (Buber, 1974, p.13). O encontro é ato de acontecimento, sempre dialógico, e revela a totalidade do homem.

Buber trata também do encontro pedagógico. Diferente da intenção pedagógica, esforço do educador para obter resultados, o encontro pedagógico se refere a uma postura do professor diante das necessidades concretas do aluno, ajudando-o a posicionar-se perante o mundo. Implica em

responder, responder com responsabilidade, dar uma reposta que provavelmente vai mais além da alternativa da pergunta. A missão do professor não é ditar o que seja bom ou mal de uma forma geral, e sim a de responder, responder a uma pergunta concreta. (Buber, 2004, p.41) $)^{3}$

A partir de um clima de confiança, o educador participa da vida dos alunos, para além da intenção pedagógica, e assume a responsabilidade que deriva do encontro pedagógico.

Para Buber (2009), o verdadeiro educador tem por objetivo desenvolver as qualidades do educando, e "sabe que isto não é possível através da imposição de sua vontade e de suas ideias sobre o outro, mas somente se for capaz de realmente 'escutar' ao outro, de estabelecer um diálogo autêntico" (pp.26-27), em que cada participante tem em mente o outro ou os outros, na sua presença e no modo de ser, e a eles se volta a fim de estabelecer - entre eles e consigo próprio - uma reciprocidade viva (Buber, 1974, p. 53).

\footnotetext{
${ }^{2}$ Original em espanhol. Tradução nossa.

${ }^{3}$ Original em espanhol. Tradução nossa.
} 


\section{pro.posıções}

\section{2 - De como ver e escutar: estratégias metodológicas}

O referencial teórico-metodológico construído permitiu delinear um olhar crítico e reflexivo para analisar práticas e interações nas sete instituições pesquisadas que constituíram o campo da pesquisa - três creches, três pré-escolas e uma escola de Ensino Fundamental que tem turmas de pré-escola - e identificar se se configuravam como espaço de encontro, presença, diálogo e escuta de e entre adultos e crianças.

Segundo Buber (2009), há três formas de perceber o outro: a observação, a contemplação e a tomada de conhecimento intimo. Esses conceitos orientaram a postura dos pesquisadores no sentido de ter presença, ver o que não foi evidenciado, escutar para além do dito, captar sutilezas e positividades em contextos ásperos, buscando, assim, tomar conhecimento íntimo, mais do que observar e descrever. A tomada de conhecimento íntimo requer uma atitude receptiva, de abertura e aceitação, de forma a ver o outro não como objeto, mas como pessoa, diante de quem o pesquisador deve responder com a investigação que realiza e suas implicações (pp.42-43).

Mas o que seria a escuta e a resposta responsável? O caminho é apontado por Buber (2009): "aquele que vive dialogicamente, alguma coisa é dita no decorrer habitual das horas e ele se sente solicitado a responder" (p. 54). A resposta responsável parte da escuta do outro. O planejamento, o espaço, as relações cotidianas, as propostas e as práticas pedagógicas contribuem para alcançar uma resposta que faça sentido para creches, pré-escolas e escolas, para as crianças e os adultos que com elas atuam. "Educação é relação" que acontece na dinâmica de "voltar-se para o outro" como ele é (Buber, 2012, p. 93) e não como desejo que seja. É o meio para captar o outro. Esse foi um desafio teórico-metodológico que norteou a investigação.

No percurso metodológico, além de construir um olhar e uma escuta para captar e analisar crianças e adultos, a pesquisa procurou identificar ambiguidades, contradições, problematizar os achados a partir da leitura de Buber. Nesse processo, foi possível ver encontros e desencontros nas práticas, nas rotinas e nas interações.

A metodologia se apoiou também na sociologia da infância - em especial em Corsaro (2011), Ferreira (2008) e Sarmento (2008) - concebendo as crianças como atores sociais, e a infância como construção histórica, social e cultural, em que as relações com o mundo dos adultos e as interações com os pares são fundamentais nos diversos contextos de produção de 


\section{pro.posıções}

suas identidades. Com base nesses autores, os pesquisadores se mantiveram em estado de alerta, procuraram conhecer as crianças, de modo a escapar do adultocentrismo.

Ao observar as crianças em contextos escolares, o pesquisador se arrisca a vê-las só como alunos e a partir do horizonte adulto. O desafio enfrentado nessas pesquisas foi o de buscar vê-las como crianças, para além de conceitos ou preconceitos dos pesquisadores e para além de uma perspectiva adultocêntrica (Sarmento, 2008). Isso exigiu dos pesquisadores o movimento - nunca fácil, nem sempre bem-sucedido - de se colocarem do ponto de vista da criança, tentando descentrar seu olhar de adulto para entender as falas, os gestos e as produções infantis (Ferreira, 2008). A sociologia da infância contribuiu, ainda, para a entrada no campo (Corsaro, 2005) e para o movimento de compreensão das "atividades ou rotinas, valores e preocupações que as crianças produzem e compartilham com outras crianças" (Corsaro, 2011, p.128).

Nas creches e nas pré-escolas foi preciso ver e ouvir. Ver: observar, construir o olhar, captar e procurar entender, reeducar o olho e a técnica. Ouvir: escutar o que foi dito e o não dito, valorizar a narrativa, entender a história. Ver e ouvir foram ações de pesquisa cruciais para compreender gestos, discursos e ações. Esse aprender de novo a ver e a ouvir (a estar lá e estar afastado; a participar e anotar; a interagir enquanto observa a interação) requer sensibilidade e teoria, produzidas na pesquisa, na trajetória vivida e no cotidiano. Nesse processo, para enfrentar os desafios teórico-metodológicos da pesquisa com crianças, o diálogo com vários campos do conhecimento - neste caso, com a filosofia e a sociologia pode oferecer importantes ferramentas conceituais. O material empírico foi produzido no âmbito do projeto "Estudos Comparativos de Interações, Práticas e Modos de Gestão em

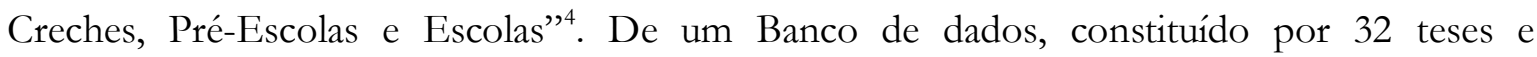
dissertações apresentadas de 2004 a 2013, este artigo focaliza 7 dissertações e 1 tese de doutorado que investigaram práticas e interações na Educação Infantil. Essas pesquisas são revisitadas a partir do pensamento de Martin Buber, filósofo do diálogo, objetivando a construção de um outro olhar norteador das análises, ampliando e complexificando as referências anteriores.

A escolha das instituições se deu a partir do critério de positividade do trabalho pedagógico: foram indicadas pelas Secretarias de Educação, no caso das públicas; e por serem

\footnotetext{
${ }^{4}$ Grupo de Pesquisa Infância, Formação e Cultura/INFOC (Kramer \& Nunes, 2014). O projeto contou com apoio do CNPq e da FAPERJ.
} 


\section{pro.posıções}

de reconhecida qualidade, no caso da comunitária e da institucional. Em todas as pesquisas foram feitas observações, escuta das crianças e entrevistas com professores, gestores e auxiliares. O tempo de permanência dos pesquisadores foi de, no mínimo, 80 horas. Os procedimentos para coleta, registro, seleção do material de campo incluíram, com base no referencial teórico-metodológico: cadernos de campo com anotações densas, fichas de campo com notas metodológicas, gravações transcritas, fotografias e acervos, e materiais pedagógicos das turmas e das instituições.

A pesquisa se apropriou, para a análise do material empírico, do conceito de evento, proposto por Kramer (2009):

No âmbito da sociologia da infância, Corsaro (1985) define eventos de interação na educação infantil como sequências de ações compartilhadas que começam com o conhecimento da presença de dois ou mais atores que se relacionam em alguma área e suas tentativas abertas de chegar a um sentido comum. ... A partir da concepção de linguagem de Bakhtin, trabalhamos com o evento no sentido de acontecimento discursivo (p.21).

Assim formulado, o conceito de evento se aproxima da noção de reciprocidade em Buber, baseado na presença de integrantes do evento da relação. Esse referencial norteou a análise dos eventos.

De posse da abordagem teórica e do material empírico, os itens a seguir trazem as recorrências nas instituições pesquisadas, focalizando encontros e desencontros entre crianças e adultos.

\section{Encontros e desencontros nas interações e nas práticas em creches}

Com o objetivo de compreender as relações dos adultos com as crianças e das crianças entre si, foram realizados estudos em três creches - uma pública, uma institucional e uma comunitária - que atendiam crianças de 4 meses a 3 anos.

A creche pública (Creche S), situada na capital do estado, está estruturada em 4 turmas, abrangendo turmas de bebês, com um total de 45 crianças de até 3 anos. A metodologia incluiu observações e entrevistas com gestores, professores e auxiliares. Foi também realizado um grupo focal com 20 profissionais da instituição (Scramingnon, 2011). 


\section{pro.posıções}

A Creche R1 funciona em uma instituição pública, na capital do estado. Atende 60 crianças entre 6 meses a 5 anos. A turma pesquisada tinha 15 crianças entre 1 ano e 3 meses e 2 anos e 7 meses e 3 profissionais: uma professora graduada em Pedagogia e com pósgraduação, e 2 auxiliares cursando Pedagogia. Foram realizadas observações durante 3 meses (Roncarati, 2012).

A creche comunitária (Creche R2) está situada na capital do estado e atende cerca de 60 crianças de 4 meses a 2 anos. As professoras têm o Curso Normal e estão concluindo Graduação em Pedagogia; as auxiliares estão iniciando a Graduação em Pedagogia. As observações foram diárias, realizadas durante um mês (Roncarati, 2012).

O estudo na Creche R1, voltado para as crianças e as práticas educativas, identificou aspectos do trabalho com educação de crianças pequenas, relativos ao corpo, ao afeto, às emoções e às comunicações não verbais dos bebês.

\section{O largo sorriso de José}

Estava sentada no chão da oficina Movimento e José se aproximou de mim, falando. Não compreendi o que ele me disse. Eu lhe disse: "Não entendi, José! Repete, por favor...!" Ele então se jogava nos blocos de espuma sorrindo e em seguida retornava, falando a mesma coisa - que eu continuava sem entender. Pedia para ele repetir e ele fazia novamente o mesmo movimento nos blocos de espuma e voltava a falar comigo. Fizemos isso 7 vezes. Ele ia e voltava. Eu [a pesquisadora] quis incluir a Auxiliar na conversa, para...ver como ela buscaria compreender a sua fala e disse ao José, um pouco alto, para a Auxiliar ouvir: "Fala para a Carla, José, para ver se ela entende!" Carla se aproximou de nós, solícita a escutar José e fez várias tentativas para compreender o que ele queria dizer. Perguntava várias coisas que pareciam se aproximar das palavras que dizia....José sorria diante das perguntas da Auxiliar e repetia a sua frase. Repetiu umas 15 vezes, também solícito a nos ajudar a compreendê-lo. Até que Carla conseguiu pegar a ideia da sua fala. Ela supôs que tinha alguma coisa a ver com patati-patatá. Quando ela disse: "É do desenho patati-patatá?", José deu um largo sorriso. Ele nos comunicou que ela tinha compreendido alguma coisa! Ela disse: "É isso? Patati-patatá?!" Ele deu outro grande sorriso, parecendo feliz em ter sido compreendido. Em seguida disse outra frase. Pareceu estar seguro para travar um diálogo: talvez estivesse sentindo-se compreendido! Sentir-se compreendido, vivenciar o interesse do adulto pelo que comunica, ver o adulto esforçando-se para compreendê-lo parece tê-lo estimulado a iniciar uma conversa - ou uma brincadeira de conversa. (Creche R1, 2012, p. 62)

O evento acontece em uma creche institucional que atende funcionários de uma entidade pública. A turma, de crianças de 15 e 24 meses, participa da Oficina Movimento. Observamos como a escuta e a relação dialógica se dão de fato. Ao escutar a criança, o adulto a instiga e estimula a prosseguir, tentando, descobrindo, agindo no mundo. A auxiliar e o 


\section{pro.posições}

menino são como parceiros em um acontecimento da vida (Buber, 2009). Ela não se contenta com o que parece ser, mas vai ao encontro do que é. E é isso que faz nascer o sorriso nos lábios do menino. O esforço da Auxiliar para compreender José libera forças criativas que o levam a prosseguir no diálogo. Isto mostra que as crianças se comunicam, dialogam entre si e estão abertas para o outro. A relação dialógica sempre nos surpreende, porque é uma resposta. Assim, se a vida não nos surpreende é porque perdemos a capacidade de ser dialógicos e deixamos de sentir. No evento, temos o inusitado por meio da relação com o outro na presença do outro que sensibiliza e surpreende.

Em outra creche pesquisada, mais uma situação positiva se revela.

Ela aproveita para andar aqui.

É cedo pela manhã e a turma do B2 está com 8 crianças, no pátio. As crianças estavam brincando livremente no chão ou explorando movimentos corporais no momento em que a professora pegou um livro e disse: "Pessoal, vamos ouvir a história do leão?" As crianças imediatamente olharam para a professora e foram sentar-se junto a ela, mostrando-se interessadas na proposta. Joana, porém, não se juntou ao grupo e ficou andando de uma ponta a outra do pátio. Joana caminhava cautelosamente, olhando para o chão, parecendo muito atenta ao seu movimento. No meio do trajeto que fazia havia um leve desnível no qual ela passava com cuidado e, quando caminhava na direção do declive, assumia uma velocidade maior nos seus passos, o que a levava a dar um suave sorriso. A professora observou a menina antes de começar a contar a história sem, contudo, chamá-la para participar. Joana andou de um lado para o outro durante toda a história, absorta no seu movimento. Ao terminar a história e percebendo que eu [a pesquisadora] observava a movimentação da menina, a professora disse: "Joana começou a andar com quase um ano e quatro meses... Eu conheço a casa dela. Ela mora numa casa tão pequena! É um quadradão onde mora um monte de gente...! Ela não tem espaço para caminhar lá, por isso fica andando assim aqui. Ela aproveita para andar aqui”. (Creche R2, 2012, p. 65)

Segundo a professora, então, a necessidade maior de Joana era caminhar e não ouvir a história do leão. A professora respeita a necessidade da criança, permite que ela permaneça no seu movimento de liberdade. Não há coação por parte da professora. Joana estava integrada ao grupo, mesmo estando envolvida em outra situação, e teve a sua liberdade respeitada. A professora permitiu que Joana entrasse em contato consigo, com suas necessidades por meio do movimento, valorizando sua autonomia e expressão.

$\mathrm{Na}$ mesma direção, ao entrevistar profissionais de creches públicas com condições de funcionamento bastante desfavoráveis, foram observadas iniciativa e atuação de professoras no sentido de garantir as ações das crianças.

Nós fechamos a rua com o nosso carro. 


\section{pro.posições}

Nós fechamos a rua com nosso carro um dia sim, um dia não para as crianças brincarem porque nós não temos área externa. A gente luta para conseguir uma área aqui em cima, algum espaço do lado de fora, porque a gente não tem e este terreno é todo da prefeitura. Os moradores sabem que fechamos a rua porque as crianças estão brincando. (Creche S, 2011, p. 70)

O evento evidencia a responsabilidade do adulto: da fala emerge a preocupação com a qualidade do trabalho com as crianças e a garantia de espaço e tempo da brincadeira e de interações. Há sensibilidade do adulto para entender a importância das experiências das crianças e as alternativas criadas dentro dos limites daquela instituição.

Contudo, nas observações foram identificadas também ambiguidades, práticas que nem sempre levavam em conta as crianças e suas possibilidades de interação.

Vamos brincar de massinha?

Chegando à sala de atividades manuais e plásticas, a professora perguntou às crianças: "Vamos brincar de massinha?" Enquanto perguntava, segurava o pote de massinha, mostrando-o às crianças, sentadas à mesa. Estavam a uma distância entre si que não favorecia as interações umas com as outras. Sem esperar a réplica das crianças...a professora lhes indagou: "A massinha é que cor?" Ao que ela mesma respondeu em seguida enfaticamente: "Amarela!" Seguiu distribuindo às crianças sentadas nas cadeiras os pedaços da massa: "Massinha amarela para você, massinha amarela para você, massinha amarela para você, massinha amarela para você, massinha amarela para você, massinha amarela para você..." Até todos terem recebido. Após a distribuição, perguntou: "Quem quer palitinhos?" Sem esperar a manifestação das crianças, perguntou, emendando a pergunta anterior: "Quantos vocês querem? Dois? Um, dois!!" E foi distribuindo os palitinhos de sorvete: "Dois para você: um, dois!" "E você, quantos quer? Dois? Um, dois!" Sua fala seguiu dessa forma até que uma das crianças imitou a sua fala: “Um, dois!" A exploração da massinha ocorreu em silêncio, quebrado por vezes pela professora, que dava um comando do que as crianças deveriam fazer com a massinha. (Creche R1, 2012, p.73)

Haveria possibilidade de escutar as crianças, ver sua postura corporal, suas expressões e o silêncio, o que não ocorreu. Monólogo disfarçado de diálogo, em que a intenção pedagógica se sobrepôs ao encontro pedagógico. Predominaram comandos repetitivos na fala da professora e o dobrar-se em si mesmo, de que fala Buber, retração que admite o outro apenas como uma parte de si. Sem ouvir o outro, sem dialogar, a professora só ouve a si própria.

As relações geram diversas aprendizagens. As crianças e os adultos aprendem a se expressar, a perceber que suas expressões desencadeiam respostas e a se colocar em relação. Afinal, o que de fato, educa e ensina? Buber (2004) afirma que "os elementos educam: o ar, a luz, a vida das plantas e dos animais; as relações também educam. O verdadeiro educador tem 


\section{pro-posıções}

em conta tudo isso, mas precisa estar diante da criança, como um desses elementos” (p. 20). As aprendizagens decorrentes da exploração dos materiais e dos objetos são importantes, mas as aprendizagens advindas das relações são fundamentais para a constituição do sujeito e para a humanização.

\section{Encontros e desencontros nas interações e nas práticas em pré-escolas}

Visando também conhecer e compreender as relações dos adultos com as crianças e das crianças foram realizados estudos em quatro pré-escolas públicas que atendiam crianças de 4 e 5 anos. Duas dessas instituições configuravam-se como pré-escolas e duas integravam escolas de Ensino Fundamental.

A Pré-Escola B está instalada em um parque público, na capital do estado. Funciona em tempo integral e recebe 100 crianças de 4 e 5 anos, distribuídas em 4 turmas. Desenvolvida como estudo de caso, as estratégias metodológicas da pesquisa foram: análise de documentos, descrições do espaço físico, observação do cotidiano, das práticas e das interações, além dos desenhos das crianças. A pesquisa de campo foi desenvolvida durante 6 meses (Barbosa, 2004).

A Pré-Escola $M$ está inserida em uma escola pública de Ensino Fundamental, onde funcionam 4 turmas de Educação Infantil - 2 para crianças de 4 anos; 2 para crianças de 5 anos - e 12 turmas do primeiro ciclo e dos 2 primeiros anos do segundo ciclo. Foram pesquisadas 2 turmas de Educação Infantil no turno da manhã, durante 6 meses, tendo sido realizadas observações e entrevistas (Mello, 2008).

A Pré-Escola $T$ integra a rede pública de um município situado na Região Metropolitana. Na turma pesquisada, havia 15 crianças de 4 anos e 1 professora. As estratégias metodológicas adotadas foram: observação, fotografia, entrevista com a equipe da Secretaria Municipal; questionário para obter dados da cobertura e do atendimento. Foram realizadas observações durante 8 meses (Toledo, 2010).

A Escola L integra a rede pública de um município da Região Metropolitana. Tem 33 turmas, sendo 2 de Educação Infantil. A maioria das crianças da escola é afrodescendente. Foram realizadas oficinas com as crianças, entrevistas com os professores, análise dos acervos 


\section{pro.posıções}

e dos materiais pedagógicos, bem como observações durante 6 meses em turmas de Educação Infantil e primeiros anos do Ensino Fundamental (crianças de 5 a 8 anos). Os eventos deste texto referem-se às turmas de Educação Infantil (Lima, 2006).

Com a atenção voltada às crianças de 4 a 6 anos, foram pesquisadas 3 pré-escolas públicas, situadas em municípios diferentes. Pode-se observar que situações de criação e diálogo conviviam com atividades instrucionais que não favoreciam as manifestações infantis.

Observações feitas na Pré-Escola B permitem entender como as crianças e os adultos que interagiam com elas usam o espaço, o que fazem, falam, brincam.

Faz de conta.

Três meninas e três meninos estão brincando na casinha. São dois grupos: os meninos e as meninas. São crianças das turmas A e B. Uma menina está se arrumando e mexendo em uma bolsa. Outras duas fazem comida, usando as coisas que as professoras fizeram para enfeitar a festa do folclore: churrasco/cocada/cuscuz. Tudo é encaminhado para as crianças. Mary (a mãe) e Mel (a filha) brincam de fazer comida e arrumar a casa. Dois meninos brincando são pai (Mat) e filho (Raf). O pai faz comida para o filho. Bel, a menina que arrumava a bolsa, agora penteia uma boneca. Parece que está brincando sozinha. Mas logo põe a bolsa no ombro e vai até as meninas e diz que quer comprar comida. Mary e Mel entendem o enredo: ao mesmo tempo, são donas da loja que vende comida e continuam mãe e filha. Mat, o menino que era o pai, vê a brincadeira das meninas, passa a ser filho e diz: "papaizinho, o que eu vou comprar"? Raf logo entende que agora ele é o pai e não discute, assume seu papel e diz: cachorro quente. Raf vai até às meninas e diz que quer três cachorros-quentes... (Pré-Escola B, 2004, p. 112)

O conceito de "tomada de conhecimento íntimo" (Buber, 2009, p. 42) permite entender o que mostram as interações: o outro não é um objeto separado de mim, mas alguém que diz algo a mim. E porque ele me diz algo, devo a ele uma resposta. É o que faz Raf ao ter plena atenção para Mat que, com uma frase, muda o enredo e se torna filho. Sem questionar, Raf acolhe Mat no seu novo papel, transformando sua posição na trama.

Tal é para Buber (2009) o caminho para que o homem se torne humano: reconhecer o outro e dar a ele uma resposta responsável. As crianças parecem saber disso. No seu faz de conta, há palavras, perguntas, diálogo autêntico, numa reciprocidade viva. Esse evento expressa a capacidade dialógica das crianças.

Mas a invisibilidade da criança também foi recorrente, como mostram eventos da Préescola M, uma instituição pública situada na capital, e da Pré-escola T, situada na Região Metropolitana. 


\section{pro.posições}

Só vou dar para quem estiver anjinho

Pierre, em uma das mesas, começa a amassar o giz com o relógio de madeira. Prof. Maria levanta, vai até ele e diz: Vem, vem para a roda. Ele se refugia. Maria diz: Ah, você quer ficar no hipopótamo? Pierre não voltou para o lugar e se escondeu atrás do computador. Maria disse: Eu não vou trazer surpresa para quem não está bonzinho. Hoje nós vamos comer bolo da Íris que sobrou de ontem, da festa do folclore e eu só vou dar para quem estiver legal. Íris diz [imitando uma fala de Maria]: Só vou dar para quem estiver anjinho. Rapidamente o menino volta para a roda. (Pré-Escola M, 2008, p.88)

Nesse caso houve imposição de uma norma sem explicação, desconhecimento da alteridade do menino. Faltou espaço para interesses diversos. Ao invés de um convite, a criança recebeu uma ameaça, foi chantageada com possíveis presentes e comida. Ao invés de ser chamada à roda pelo que o grupo fazia, as brincadeiras, a curiosidade, foi atraída por uma recompensa externa. A professora desconsiderou o essencial: o encontro. A lógica da coação, da ausência de liberdade de escolha, da moralização é repetida pelas próprias crianças.

E foram recorrentes também, nas pré-escolas pesquisadas, situações de humilhação, difíceis de observar, de aceitar, de não intervir.

Quem falar vai sentar no chão frio.

Quem falar vai sentar no chão frio! Deixa o velcro do tênis! Quem é essa criança feia? Eu acho que ela nunca teve um tênis! Pode ficar aqui de pé do meu lado! Quero ver você mexer no velcro agora! (Pré-escola T, 2010, p.60)

A fala da professora - mais do que o chão a que ela se refere - traz um conteúdo humilhante e a ameaça de castigo físico. A criança é submetida a um constrangimento que remete a denúncias em situações em que são apagadas as necessidades individuais e fica vedado o espaço de convivência com a diversidade.

Buber (2009) aponta para a atrofia da existência pessoal (p. 67) em setores coletivos como o militarismo. Essa atrofia pode ser percebida no evento acima. A criança está atada (p. 66) à instituição por forças despersonalizantes que aniquilam desejos e impõem o anonimato. Buber, ao contrário, compreende a educação como dimensão fundamental para formar a comunidade, onde as pessoas viveriam de forma mútua, com um centro vivo comum. A comunidade, espaço de solidariedade, de reciprocidade, de diálogo.

Crianças! Amigos! 


\section{pro.posições}

No final da elaboração de um texto coletivo, a professora suscita a expressão de alegria, amizade, autoria.

Quem inventou essa história?, pergunta a professora.

A gente!

E vocês são o quê?

Crianças! Amigos! (Pré-Escola B, 2004, p. 69)

O evento parece banal. Entretanto, ele evidencia aspectos centrais da vida das crianças e dos adultos: o reconhecimento, a autoria e a amizade. A presença e a reciprocidade podem acontecer sem palavras. Nesse caso, ela foi percebida pela professora que favoreceu o diálogo, em que, segundo Buber (2004) se constrói cumplicidade, parceria e confiança no outro.

O que acontece entre as crianças é encontro. Elas reconhecem suas possibilidades. Ao reconhecerem a presença e a participação umas das outras, elas se reconhecem a si mesmas e, a partir desse reconhecimento mútuo, de si e do outro, se estabelece uma relação de encontro.

Mas outras situações são também parte do cotidiano escolar.

O chapéu do soldado é verde

(Após a brincadeira de soldado, a professora sugere que as crianças façam chapéus) Maria: Olha... vocês vão fazer assim. (dobra o papel na frente deles, na mesa). Lucio: Eu não sei. Maria: Sabe sim. Olha, a Vivian vai te ensinar. (enquanto isso, Maria vai de mesa em mesa dobrando.) Maria: Agora, eu vou pegar a cola. (Maria pega a cola e passa de mesa em mesa colando as pontas): Oh, agora é só pintar. O chapéu do soldado é verde. Uma criança diz: A fulana pintou de amarelo. Maria: Ah, vai ficar feio. O chapéu do soldado é verde. (Cada criança vai pintando o chapéu de um jeito, mas da mesma cor) Pierre diz: Olha, ela está pintando de outra cor. (Elaine que pintava de vermelho, depois da observação, pega o verde). (Enquanto isso, da outra mesa, Maria diz: Marcha soldado, cabeça de papel, quem não tiver chapéu, não vai marchar no meu quartel. Diz isso porque percebe que Túlio não estava realizando a atividade). Juliana diz: Olha aqui (mostrando seu chapéu). Maria diz: Que lindo soldado, Juliana. (Pré-Escola M, 2008, p.115)

Os conceitos de intenção pedagógica e de encontro pedagógico são empregados por Buber (2004) para se referir à prática pedagógica e à relação professor-aluno. Intenção é o esforço do educador em obter resultados pedagógicos; encontro implica em responsividade com responsabilidade diante de uma situação vivida pelo aluno. Para o autor, isto só é possível num clima de confiança tecido quando o educador participa da vida dos alunos - que o aceitam como pessoa -, assumindo a responsabilidade derivada dessa participação, "ruptura da incomunicação" (p. 42). Responder implica em ter liberdade para fazê-lo, em conhecer o aluno e saber intervir. Importa, na prática educacional, atingir os objetivos, cumprir o currículo e 


\section{pro.posições}

alcançar os resultados desejados. Mas, para Buber, o cerne da educação é contribuir para a formação do caráter, que se concretiza no encontro pedagógico.

Contudo, a dificuldade de responder, de estar presente e estabelecer vínculos, aliada a um cotidiano massacrante, pode gerar situações limite de apagamento do outro e de esquecimento do seu papel como educador, pai, adulto ou professor.

\section{Olhem para a TV}

As meninas da quarta série entraram na sala pedindo para ajudar a professora. Eram quatro meninas. A professora foi clara: Vejam se conseguem fazer eles assistirem o filme. Mais que depressa, elas colocaram todos sentados e disseram em tom ríspido: Olhem para a tv. As crianças olhavam e logo depois começavam a conversar. As meninas da quarta série continuaram insistindo. Luis se levantou e começou a falar alto. Uma das meninas da quarta série o chamou e disse: Você quer fazer um desenho ali na mesa? Ele disse: Quero. (Assim ele fez). Logo, outras crianças viram e começaram a pedir para desenhar. Ana interveio e disse: Ah... não. Podem tratar de ver o filme. (Pré-M., 2008, p.86)

A ocupação se contrapõe à participação. Sem confiança, apenas se ocupando, o educador não participa da vida do aluno. A participação implica em responder ao aluno, antes mesmo de querer influenciá-lo (Buber, 2004, p.41).

Escutar o outro é preciso para que haja diálogo autêntico, em que cada pessoa leva em conta os outros, sua presença, modo de ser, se volta para o outro e entre eles é tecida a reciprocidade (Buber,1974). O reconhecimento compreende a percepção e a aceitação do outro, libertando-se da indiferença em relação a ele.

Mas escutar e reconhecer o outro exige um aprendizado que se traduza na prática, o que por vezes se mostra contraditório. Assim, embora o objetivo da Escola L, com expressiva maioria de crianças afrodescendentes, fosse manter projetos voltados para a aceitação e o respeito ao outro, foram observados eventos que negam esse intuito.

Paz: busca de todos!

Na terceira semana de aula, o tema do mural foi substituído por outro alusivo ao folclore. Acompanhando a frase "Folclore: Cultura de um Povo", encontrava-se a gravura relacionada ao reisado, em seguida substituída por outra, referente à Paz: "Paz: busca de todos!" frase acompanhada pela imagem de uma família branca (mãe, pai, bebê), passando a ideia idealizadora de uma família, branca, nuclear. (Escola L, 2006, p. 158) 


\section{pro.posıções}

Para essa escola, o exercício da alteridade é fundamental, mas a alteridade não se expressa ainda em todas as práticas e interações cotidianas, como revela o evento acima.

O desafio está colocado. Como propõe Buber (2009),

para podermos sair de nós mesmos em direção ao outro é preciso ... partirmos do nosso próprio interior. É preciso ter estado, é preciso estar em si mesmo. O diálogo entre meros indivíduos é apenas um esboço, é somente entre pessoas que ele se realiza. (p. 55)

A título de considerações finais: o que fazemos com o nosso conhecimento?

Os resultados da pesquisa sobre práticas e interações em creches, pré-escolas e turmas de pré-escola em escola de Ensino Fundamental, baseada na filosofia do diálogo de Martin Buber e na sociologia da infância, indicam positividades, negatividades e ambiguidades.

As positividades puderam ser percebidas na escuta sensível das crianças pelos adultos, na sua relação dialógica, na consideração da presença do outro, no respeito, na responsabilidade e no compromisso com a qualidade. As negatividades foram observadas na invisibilidade das crianças, nas situações de constrangimento e humilhação pelos adultos nas ações cotidianas, com pouca possibilidade de criação e expressão infantis.

Tanto as creches quanto as pré-escolas apresentaram ambiguidades, evidenciadas em práticas repetitivas, voltadas a atividades mecânicas de ensino, sem levar em conta as interações infantis. Mas predominaram negatividades nas pré-escolas e positividades nas creches. Essa conclusão leva a indagar até que ponto a maior ou menor proximidade, espacial e temporal, da Educação Infantil em relação ao Ensino Fundamental produz práticas em que o ensino ocupa o que deveria ser a centralidade educativa: as crianças e suas interações. Esse tema coloca em questão a própria identidade da Educação Infantil, desafio enfrentado nas últimas décadas no Brasil e que se refere à qualidade do trabalho e à necessária formação dos profissionais.

Considerando que as instituições pesquisadas foram escolhidas pela sua positividade e pelo compromisso com a qualidade - ou seja, se mostraram abertas ao diálogo e à mudança as concepções e as práticas estudadas na filosofia de Buber favorecem a indicação de caminhos por onde se poderia abrir a estreita aresta para o conhecimento, a sensibilidade e o agir ético de crianças e adultos e com eles. 


\section{pro.posıções}

Para Buber (2009), é preciso tomar contato íntimo, ter atenção, assegurar a presença de adultos e crianças nas práticas. Vincular-se, ter disponibilidade para acolher, ser humano, atuar entre, na estreita aresta entre eu e o outro (nós e as crianças). Estreita aresta é o que liga, conecta, vincula (Buber, 1974). Vincular-se e sustentar os vínculos; tratar o outro como fim, não como meio, com alegria, expressão máxima do ser humano; aliar conhecimento e sentimento; ter empatia, sentir a dor do outro, assumindo que a marca distintiva do homem não é a razão, mas, sim, nossa capacidade de relação (Kramer, 2013).

Uma educação humanizada, baseada no diálogo, na relação com o outro, com escuta e resposta responsáveis deve agir na direção dos outros. A pesquisa evidenciou resposta responsável, mas também desumanização, com formas rudes e ásperas no trato com as crianças.

Muitas práticas observadas mostraram repetição de ações sem reflexão. Buber (2004) indaga: "Em que se baseia tua cosmovisão?; Que fazes com tua cosmovisão?”(p. 36). Saber qual a visão de mundo que nos orienta pode levar a não repetir padrões, mas a formar, transformar, criar. Não se trata de justapor diferentes visões, mas de agir com solidariedade e reciprocidade. No dia a dia das instituições, diversas visões de mundo podem não se hierarquizar ou se anular. Ao contrário, no encontro delas torna-se possível encontrar ou traçar caminhos para a alteridade.

Aprender a se comunicar com o outro, a se expressar e estabelecer diálogos verbais ou não verbais é fundamental para bebês e crianças maiores que precisam do outro para se constituir e aprender a atuar como pessoas. Ajudá-los nessa árdua e prazerosa construção é uma ação educativa essencial, abertura que se dá não só no aprendizado, mas no encontro, onde à educação cabe exercer seu papel voltado para o diálogo, o respeito e o reconhecimento do outro.

\section{Referências Bibliográficas}

Barbosa, S. N. F. (2004). Nas tramas do cotidiano: adultos e crianças construindo a Educação Infantil (125 pp.). Dissertação de Mestrado em Educação, Pontifícia Universidade Católica do Rio de Janeiro, Rio de Janeiro. 


\section{pro.posições}

Buber, M. (1974). Eu e tu (248 pp., 2a ed., N. Zuben, trad. do alemão, introdução e notas). São Paulo: Moraes.

Buber, M. (2004). El caminho del ser humano y otros escritos (129 pp.). Salamanca: Kadmos.

Buber, M. (2009). Do diálogo e do dialógico (171 pp.). São Paulo: Perspectiva.

Buber, M. (2011). ¿Qué es el hombre? (153 pp.). México: FCE.

Buber, M. (2012). Sobre comunidade (136 pp.). Campinas: Perspectiva.

Corsaro, W. (1985). Friendship and peer cultures in the early years. Norwood: Ablex.

Corsaro, W. (2005, maio/agosto). Entrada no campo, aceitação e natureza da participação nos estudos etnográficos com crianças pequenas. Revista Educação e Sociedade, 26(91), 443-464.

Corsaro, W.A. (2011). Sociologia da Infância (384 pp., 2a ed.). Porto Alegre: Artmed.

Ferreira, M. M. M. (2008). Branco demasiado branco: reflexões epistemológicas, metodológicas e éticas acerca da pesquisa com crianças. In M. Sarmento, \& M. C. S. de Gouvea (Orgs.), Estudos da infância: educação e práticas sociais (277pp.). Petrópolis, RJ: Vozes.

Kramer, S. (Org.). (2009). Retratos de um desafio: crianças e adultos na Educação Infantil (232 pp.). São Paulo: Ática.

Kramer, S. (2013). Formação e responsabilidade: escutando Mikhail Bakhtin e Martin Buber. In S. Kramer, M. F. Nunes, \& C. Carvalho. Educação Infantil: formação e responsabilidade (pp. 309-329). Campinas: Papirus.

Kramer, S., \& Nunes, M. F. (2014). Estudos comparativos de interações, práticas e modos de gestão em creches, pré-escolas e escolas (187 pp.). Banco de Dados da Pesquisa, PUCRio.

Lima, M. B. (2006). Práticas cotidianas e identidades étnicas: um estudo no contexto escolar (267 pp.). Tese de Doutorado em Educação, Pontifícia Universidade Católica do Rio de Janeiro, Rio de Janeiro. 


\section{pro.posıções}

Mello, T. de Freitas O. de. (2008). Da mediação do professor às mediações dos sujeitos adultos e crianças - na Educação Infantil (139 pp.). Dissertação de Mestrado em Educação, Pontifícia Universidade Católica do Rio de Janeiro, Rio de Janeiro.

Roncarati, M. (2012). Perspectivas de uma educação dialógica na creche: a co-autoria da criança na construção da prática educativa (97 pp.). Dissertação de Mestrado em Educação, Universidade Federal do Estado do Rio de Janeiro, Rio de Janeiro.

Sarmento, M. (2008). Sociologia da infância: correntes e confluências. In M. Sarmento, \& M. C. S. de Gouvea (Orgs.), Estudos da infância: educação e práticas sociais (277pp.). Petrópolis, RJ: Vozes.

Scramingnon, G. (2011). "Eu lamento, mas é isto que nós temos". O lugar da creche e de seus profissionais no Município do Rio de Janeiro (131pp.). Dissertação de Mestrado em Educação, Universidade Federal do Estado do Rio de Janeiro, Rio de Janeiro.

Toledo, L. P. B. de. (2010). Relações e concepções de crianças com/sobre a natureza: um estudo em uma escola municipal (125 pp.). Dissertação de Mestrado em Educação, Pontifícia Universidade Católica do Rio de Janeiro, Rio de Janeiro.

Zuben, N. A. von. (1974). Introdução (p. I-LXXIII) e Notas do Tradutor. In M. Buber. Eu e tu (2a ed., pp. 1-78). São Paulo: Moraes.

\section{Legislação}

Lei BR n. 9.394, de 20 de dezembro de 1996. (1996). Diretrizes e Bases da Educação Nacional. Brasília: Presidência da República.

Lei BR n. 12.796, de 4 de abril de 2013. (2013). Altera a Lei n. 9.394, de 20 de dezembro de 1996, que estabelece as diretrizes e bases da educação nacional, para dispor sobre a formação dos profissionais da educação e dar outras providências. Brasília: Presidência da República.

Submetido à avaliação em 16 de outubro de 2014; aprovado para publicação em 19 de junbo de 2015. 